\title{
Treatment patterns and costs for anti-TNFa biologic therapy in patients with psoriatic arthritis
}

\author{
Jacqueline B. Palmer ${ }^{*}$, Yunfeng Li ${ }^{2}$, Vivian Herrera ${ }^{1}$, Minlei Liao ${ }^{3}$, Melody $\operatorname{Tran}^{1,4}$ and Zafer E. Ozturk ${ }^{5}$
}

\begin{abstract}
Background: Real-world data regarding anti-tumor necrosis factor alpha (anti-TNFa) biologic therapy use in psoriatic arthritis (PsA) are limited; therefore, we described treatment patterns and costs of anti-TNFa therapy in PsA patients in the United States.

Methods: PsA patients $(N=990)$ aged $\geq 18$ years who initiated anti-TNFa therapy were selected from MarketScan claims databases $(10 / 1 / 2009$ to $9 / 30 / 2010)$. Number of patients on first- $(n=881)$, second- $(n=72)$, or third- or greater $(n=37)$ line of anti-TNFa therapy, persistence, time-to-switch or modification, pharmacy and medical costs (measured per patient per month [PPPM]) for each line of therapy were observed during the 3-year follow-up.

Results: PSA patients receiving only one line of anti-TNFa therapy remained on first-line for $\sim 17$ months while those who switched to second- or third- or greater persisted on first-line for $\sim 11$ to 12 months, respectively. Time to first-line modification was longer for patients who switched to third- or greater line therapy (7 months) than those who did not switch or switched to second-line (range, 2 to 4 months). Time-to-switch and time to first-line modification was progressively shorter with each line of therapy for patients who received third- or greater line. PPPM medical costs were higher for patients who did not switch (\$322) than those who switched to second(\$167) or third- or greater (\$217) line. PPPM pharmacy costs were greater for patients with third- or greater line therapy (\$2539) than those who did not switch (\$1985) or switched to second-line (\$2045).

Conclusion: While the majority of patients received only one line of anti-TNFa therapy, a subset of patients switched to multiple lines of therapy during the 3-year follow-up period. Persistence and therapy modifications differed between these patients and those receiving only one line. Overall medical costs were highest for patients who did not switch, and pharmacy costs increased as patients switched to each new line of therapy.
\end{abstract}

Keywords: Anti-TNFa biologic therapy, DMARDs, Treatment patterns, Costs, Switch, Treatment modification

\section{Background}

Psoriatic arthritis (PsA), a type of the spondyloarthritis [1-4], is a chronic autoimmune disorder that affects the peripheral and axial joints, nails, entheses, and is commonly associated with psoriatic skin lesions $[5,6]$. Although symptoms can vary, patients with PsA often

\footnotetext{
* Correspondence: Jacqueline-1.palmer@novartis.com

Data were presented as a poster at the International Society for Outcomes Research (ISPOR) 20th Annual International Meeting, Philadelphia, PA, May 16-20, 2015.

1 Immunology and Dermatology, Health Economics \& Outcomes Research, Novartis Pharmaceuticals Corporation, One Health Plaza, East Hanover, NJ 07936-1080, USA

Full list of author information is available at the end of the article
}

suffer from joint pain, stiffness, swelling, dactylitis, nail psoriasis, and fatigue [6]. In addition, patients in the later stages of disease may experience osteolysis with destruction of the joint cartilages and boney surfaces, potentially resulting in severe deformities [7]. In the United States (US), approximately $30 \%$ of patients with psoriasis develop PsA, with the PsA prevalence estimated between 0.10 and $0.25 \%$ of the overall population $[6,8]$. PsA is associated with a number of comorbidities, including hypertension, cardiovascular disease, obesity, depression, and anxiety, and is linked to a decrease in the quality of life $[6,9-12]$. Direct annual healthcare costs related to PsA were estimated to be as high as $\$ 1.9$ 
billion in 2012 [6]. Total indirect healthcare costs accounted for 52 to $75 \%$ of total healthcare costs, with both direct and indirect costs reported to increase with disease severity [6].

The American Academy of Dermatology (AAD) and The European League Against Rheumatism (EULAR) treatment guidelines have suggested a stepwise approach for treating PsA based on symptoms, disease severity, joint involvement, and extent of inflammation [13-17]. Mild disease is typically treated with nonsteroidal antiinflammatory drugs (NSAIDs) or intra-articular corticosteroid injections [13, 17]. If inflammation is persistent, the guidelines suggest using oral nonbiologic diseasemodifying antirheumatic drugs (DMARDs), such as methotrexate (MTX) [13, 17]. If traditional DMARDs are unable to control the signs and symptoms of PsA, the use of biologics is recommended [13, 17]. Biologics approved and currently available for treating moderate-to-severe PsA include the anti-tumor necrosis factor $\alpha$ (anti-TNF $\alpha$ ) drugs adalimumab, etanercept, golimumab, infliximab, certolizumab pegol; and the interleukin 12 (IL-12) and interleukin 23 (IL-23) inhibitor ustekinumab [18-23]. These agents have been reported in numerous clinical studies as effective in managing symptoms such as dactylitis, enthesitis, and spondylitis, as well as skin and nail disease [13, 14, 17, 24-28]. Recently updated guidelines from the Group for Research and Assessment of Psoriasis and Psoriatic Arthritis (GRAPPA) have recommended specific treatments based on clinical domains of disease activity (i.e., peripheral arthritis, axial disease, enthesitis, dactylitis, skin, or nails) [25, 26, 29, 30].

Current treatment guidelines offer no guidance in terms of what sequence of anti-TNF $\alpha$ biologic therapy should be used. Patients often start with an anti-TNF $\alpha$ biologic therapy (i.e., first-line therapy) and switch to another line of therapy (i.e., second-line and third-line etc.) due to lack of effectiveness, tolerability or safety $[13,17,25,26,29,30]$. If anti-TNF $\alpha$ biologic therapy is lacking efficacy, current treatment guidelines suggest the addition or modification of nonbiologic therapy (e.g., changing dose or adding or removing a DMARD) $[13,17,25,26,29,30]$.

To date, no prior US studies have stratified administrative claims data by lines of anti-TNF $\alpha$ biologic therapy [31-35]; therefore, little is known regarding how often a patient with PsA switches from one anti-TNF $\alpha$ biologic therapy to another (e.g., first anti-TNF $\alpha$ biologic [first-line] to second anti-TNF $\alpha$ biologic [second-line]), and whether a connection exists between treatment modification and switching. In addition, multiple factors may affect medical and drug costs such as functional disability, disease severity, treatment response, dosing schedule, and switching or modifying therapy [6, 24, 27, $34,36,37]$. Although several studies have reported the annual direct costs of anti-TNF $\alpha$ biologic therapy (i.e., drug and administration costs) for PsA treatment [34, 35, $38,39]$, none have investigated the relationship between healthcare costs and switching of anti-TNF $\alpha$ biologic therapy in patients with PsA. Previous US claims database analyses have assessed the treatment patterns and healthcare costs of patients with PsA who received anti-TNF $\alpha$ biologic therapy over a 1-year period [31-35, 38-40]. These studies evaluated the frequency and duration of anti-TNF $\alpha$ biologic therapy (i.e., persistence, discontinuation, restarting and/or switching anti-TNF $\alpha$ biologic therapy), and the addition of another medication to the antiTNF $\alpha$ biologic therapy [31-35]. Although these claims studies reported treatment patterns and healthcare costs over a 1-year follow-up period, it is unclear whether these findings are maintained over more extended periods of time. Since PsA is a chronic disease, with patients typically on therapy for multiple years, the purpose of this study was to observe the treatment patterns and healthcare costs associated with anti-TNF $\alpha$ biologic therapy over a 3year follow-up period in patients with moderate-to-severe PsA identified from US claims databases.

\section{Methods}

\section{Data source}

This study utilized a retrospective observational claims database in the US known as Truven Health Analytics MarketScan ${ }^{\curvearrowleft}$ Research Databases (the Commercial Claims and Encounters Database [Commercial] and the Medicare Supplemental and Coordination of Benefits Database [Medicare] from January 1, 2005 to September 30, 2013. The Commercial Claims and Encounter Database contains the healthcare experience of individuals who are active employees and early retirees, and includes coverage under fee-for-service (FFS), point of-service (POS), and health maintenance organizations (HMOs) [41-43], including de-identified medical claims (inpatient, outpatient, and emergency room [ER]) and pharmacy claims linked to plan enrollment information. The Medicare database consists of the healthcare information of retirees with Medicare supplemental insurance paid by the employee, any out-of-pocket patient expenses, and portion of the payment [42, 43]. These databases have patient information relatd to demographics, healthcare utilization, comprehensive prescription drug information, and payment costs, and inpatient and outpatient detailed cost, use, and outcomes data [42, 43].

All study data were accessed using techniques compliant with the Health Insurance Portability and Accountability Act of 1996, and no identifiable or protected health information was extracted during the course of the study, hence, the study did not require informed consent or institutional review board approval. Data are not to be shared due to the proprietary nature $[42,43]$. 


\section{Sample selection and patient population}

The treatment identification period was from October 1, 2009 to September 30, 2010. The study population (aged $\geq 18$ years) was selected from commercial and Medicare health plan members identified with $\geq 1$ claim for an anti-TNF $\alpha$ biologic therapy of interest during the treatment identification period and with $\geq 1$ non-rule-out International Classification of Diseases, Ninth Revision, Clinical Modification (ICD-9-CM) claim for PsA (ICD-9-CM code 696.0) before the index date and after January 1, 2005. The index (initiation) date was defined as the first observed claim for use of an anti-TNF $\alpha$ biologic therapy. Patients had to be continuously enrolled with medical and pharmacy benefits 6 months prior to the index date and through the 3-year follow-up period. The follow-up period was defined as the 3 years that followed the index date. Patients with an ICD-9-CM code recorded in claims during the 6-month baseline period and the 3-year follow-up period for rheumatoid arthritis (RA) (714.x) and ankylosing spondylitis (AS) (720.0) were excluded. Patients were also excluded if they used an anti-TNF $\alpha$ biologic therapy within 6 months prior to the index date (to include only new antiTNF $\alpha$ biologic users).

Demographic and baseline patient characteristic variables Demographic continuous and categorical variables were age, gender, geographic region (Northeast, North central, South, West, Unknown), and insurance type (HMO and POS capitation, FFS], Unknown). Clinical categorical variables were comorbidities and first-line anti-TNF $\alpha$ biologic therapy. Comorbidities of interest included hypertension (ICD-9-CM: 362.11, 401.0-405.0, 437.2), hyperlipidemia (ICD-9-CM: 272.0-272.4), type 2 diabetes (ICD-9-CM: 249.0, 250.0, 357.2, 362.0, 366.41), and ischemic heart disease (ICD-9-CM: 410.0-414.0, 414.12, 414.2, $414.3,414.8$, and 414.9).

\section{Outcome measures}

The data set and outcome measures evaluated and methodology used in this study are similar to another recently published study that focused on treatment patterns and healthcare costs of patients with AS in the United States over a 3-year follow-up period [44].

The current study had four key outcomes of interest associated with anti-TNFa biologic therapy: number of patients per line of therapy; duration of treatment; time to treatment modification and healthcare resource costs associated with line of treatment (medical and pharmacy costs). For the first outcome, the number of patients on each "n" th-line of therapy (first-, second- or third) was reported. Treatment duration was measured as persistent use of an anti-TNF $\alpha$ biologic (defined as time from initiation of the treatment line to discontinuation [e.g., a gap in treatment of $>60$ days]) or as time to switch to the next treatment line, or whichever came first. Time to first treatment modification was defined as the time from initiation of an anti-TNF $\alpha$ treatment to the first modification of that treatment. Treatment modifications included an increase or decrease in dose of an antiTNF $\alpha$ biologic or DMARD, or an add-on, removal, or change of a DMARD. Healthcare resource costs were reported as medical costs (hospitalizations, office visits, ER visits) and pharmacy drug costs (anti-TNF $\alpha$ therapy and DMARDs) per patient per month (PPPM). Anti-TNF $\alpha$ therapies of interest were etanercept [19], adalimumab [18], infliximab [21], and golimumab [20]. Only antiTNF $\alpha$ therapies approved during the study period were included. Non-biologic DMARDs included azathioprine [45], hydroxychloroquine sulfate [46], leflunomide [47], sulfasalazine [48], cyclosporine [49], methotrexate [50], and the phosphodiesterase 4 inhibitor, apremilast [51].

\section{Statistical analysis}

All data were analyzed descriptively. Patient-level analyses included demographics, number of patients on one or more lines of anti-TNFa biologic therapy, number of patients initiating each anti-TNFo agent of interest, and number of patients who switched treatments (any switch or $\geq$ one switch). Subgroup analyses reported the mean (standard deviation [SD]) duration (days) patients persisted on each line of treatment, time to switch to the next line of treatment, time to the first treatment modification, and time from first treatment modification to switch. Medical costs were hospitalizations, office, and ER visits. Pharmacy drug costs included the cost of anti-TNFa biologic and DMARD treatment. The value for each medical and pharmacy outcome was calculated as total PPPM cost incurred from initiation of an anti-TNF $\alpha$ biologic treatment to discontinuation of treatment or end of the 3year follow-up period (whichever came first) divided by the number of covered members per months from initiation to treatment discontinuation or end of the follow-up period (whichever came first).

\section{Results \\ Demographics and baseline characteristics}

The final study population included 990 PsA patients who started anti-TNFo biologic therapy between October 1, 2009 and September 30, 2010 (Fig. 1). At baseline (index date), the mean (SD) average age of the study population was 49.0 (10.9) years and was comparable across the lines of therapy (Table 1). A lower percentage of females received only one line of anti-TNF $\alpha$ biologic therapy (43.9\%) compared with those who received a second- $(58.3 \%)$ or third- or greater (59.5\%) line of therapy. A higher percentage of patients with PsA in each line of therapy were from the Southern region of the United States compared with other regions, and most (81.5 \%) had FFS health insurance 
(Table 1). The most common first-line anti-TNF $\alpha$ biologic therapies used were etanercept (43.9\%) and adalimumab (44.1\%). Over the 3-year follow-up, $63.5 \%$ of patients with PsA had at least one comorbidity-the most frequently reported were hypertension (45.6\%), hyperlipidemia (37.9\%), and type 2 diabetes (22.6\%) (Table 1$)$.

\section{Persistent use and time to switch of anti-TNFa therapy}

Over the 3-year follow-up, PsA patients receiving only one line of anti-TNF $\alpha$ biologic therapy persisted on their therapy for 17.4 months (mean [SD]; 522.3 [418.9] days) while those who switched to a second- or third- or greater line therapy persisted on first-line therapy for 11.6 months (348.5 [308.7] days) or 10.8 months (325.2 [239.9] days), respectively (Table 2). Time to first treatment modification for first-line therapy was shortest for patients who received two lines of anti-TNF $\alpha$ biologic therapy (mean [SD]; 58.4 [102.7] days or 1.9 months), followed by those receiving one line of therapy (119.4 [208.7] days or 4 months) and those receiving three or

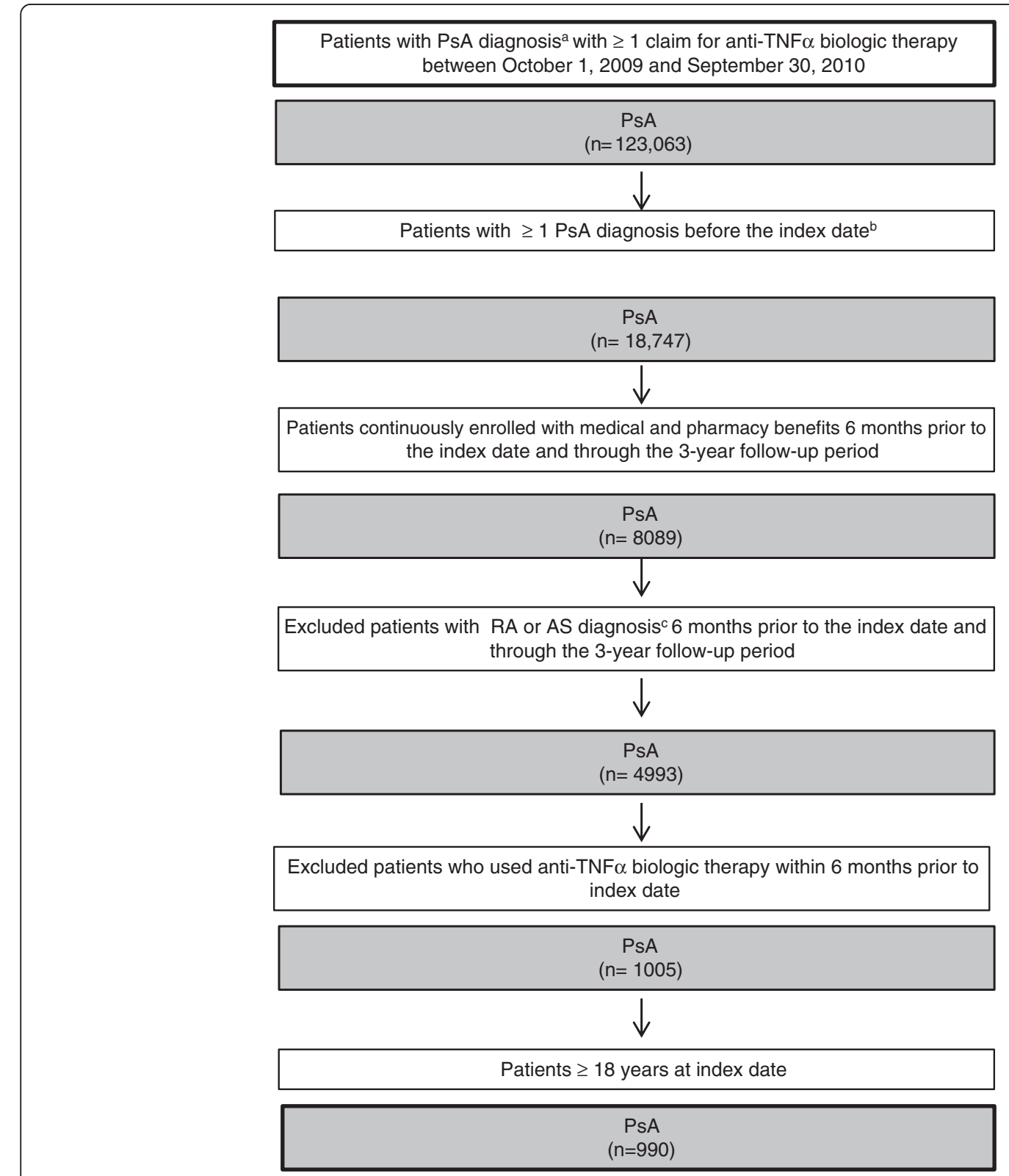

Fig. 1 Patient selection flowchart. ${ }^{a}$ The index date is the date of the use of the first anti-TNFa biologic. ${ }^{b} \mathrm{~A}$ diagnosis of PsA was established according to the ICD-9-CM code 696.0. 'The ICD-9-CM codes for RA (ICD-9-CM code: 714.x) or AS (ICD-9-CM code: 720.0) were used for diagnosis. AS, ankylosing spondylitis; ICD-9-CM, International Classification of Diseases, Ninth Revision, Clinical Modification; PsA, psoriatic arthritis; RA, rheumatoid arthritis; TNFa, tumor necrosis factor-a 
Table 1 Summary of demographics and baseline characteristics

\begin{tabular}{|c|c|c|c|c|}
\hline & $\begin{array}{l}\text { Patients With Only First-line } \\
\text { Biologic Therapy } \\
(n=881)^{\mathrm{a}}\end{array}$ & $\begin{array}{l}\text { Patients With Second-line } \\
\text { Biologic Therapy } \\
(n=72)^{b}\end{array}$ & $\begin{array}{l}\text { Patients With Third-line or } \\
\text { Greater Biologic Therapy } \\
(n=37)^{a, b}\end{array}$ & $\begin{array}{l}\text { Overall } \\
(N=990)\end{array}$ \\
\hline Age $(\mathrm{y})$, mean (SD) & $49.1(11.0)$ & $48(10.9)$ & $48.8(9.5)$ & $49.0(10.9)$ \\
\hline Female, n (\%) & $387(43.9)$ & $42(58.3)$ & $22(59.5)$ & $451(45.6)$ \\
\hline \multicolumn{5}{|l|}{ US region, n (\%) } \\
\hline Northeast & $127(14.4)$ & $11(15.3)$ & $4(10.8)$ & $142(14.3)$ \\
\hline North central & $209(23.7)$ & $11(15.3)$ & $8(21.6)$ & $228(23.0)$ \\
\hline South & $357(40.5)$ & $32(44.4)$ & $15(40.5)$ & $404(40.8)$ \\
\hline West & $182(20.7)$ & $18(25.0)$ & $10(27.0)$ & $210(21.2)$ \\
\hline Unknown & $6(0.7)$ & 0 & 0 & $6.0(0.6)$ \\
\hline \multicolumn{5}{|l|}{ Health insurance, $n(\%)$} \\
\hline FFS & $721(81.8)$ & $54(75.0)$ & $32(86.5)$ & $807(81.5)$ \\
\hline HMO and POS capitation & $137(15.6)$ & $18(25.0)$ & $5(13.5)$ & $160(16.2)$ \\
\hline Missing/unknown & $23(2.6)$ & 0 & 0 & $23(2.3)$ \\
\hline \multicolumn{5}{|l|}{ Index biologic therapies, n (\%) } \\
\hline Etanercept & $389(44.2)$ & $31(43.1)$ & $15(40.5)$ & $435(43.9)$ \\
\hline Adalimumab & $391(44.4)$ & $32(44.4)$ & $14(37.8)$ & $437(44.1)$ \\
\hline Infliximab & $67(7.6)$ & $3(4.2)$ & $7(18.9)$ & $77(7.8)$ \\
\hline Golimumab & $34(3.9)$ & $6(8.3)$ & $1(2.7)$ & $41(4.1)$ \\
\hline \multicolumn{5}{|l|}{ Comorbidities, n (\%) } \\
\hline Type 2 diabetes & $203(23.0)$ & $11(15.3)$ & $10(27.0)$ & $224(22.6)$ \\
\hline Hypertension & $400(45.4)$ & $33(45.8)$ & $18(48.6)$ & $451(45.6)$ \\
\hline Hyperlipidemia & $337(38.3)$ & $23(31.9)$ & $15(40.5)$ & $375(37.9)$ \\
\hline Ischemic heart disease & $75(8.5)$ & $4(5.6)$ & $4(10.8)$ & $83(8.4)$ \\
\hline Any of the above & $563(63.9)$ & $41(56.9)$ & 25 (67.6) & $629(63.5)$ \\
\hline
\end{tabular}

PSA, psoriatic arthritis; FFS, fee-for-service; HMO, health maintenance organization; $P O S$, point-of-service; $S D$, standard deviation; TNFa, tumor necrosis factor-a

aiologic therapy refers to the following anti-TNFa agents: etanercept, adalimumab, infliximab, and golimumab. ${ }^{\mathrm{b}}$ Among this group of patients, 18 (43\%) switched to a fourth-line of biologic treatment. ${ }^{\mathrm{C}}$ Identification was based on non-rule-out diagnoses 
Table 2 Treatment patterns for anti-TNFa biologic therapy in patients with PsA for the 3-year follow-up

\begin{tabular}{|c|c|c|c|}
\hline & $\begin{array}{l}\text { Patients With Only First-line } \\
\text { Anti-TNFa Biologic Therapy } \\
(n=881)^{\mathrm{a}}\end{array}$ & $\begin{array}{l}\text { Patients With Second-line } \\
\text { Anti-TNFa Biologic Therapy } \\
(n=72)^{\mathrm{a}}\end{array}$ & $\begin{array}{l}\text { Patients with Third-line or Greate } \\
\text { of Anti-TNFa Biologic Therapy } \\
(n=37)^{\mathrm{a}}\end{array}$ \\
\hline \multicolumn{4}{|c|}{ Persistent use of anti-TNFa biologic therapy (days), mean (SD) ${ }^{b}$} \\
\hline First-line & $522.3(418.9)$ & $348.5(308.7)$ & $325.2(239.9)$ \\
\hline Second-line & N/A & $447.3(327.6)$ & $126.8(197.9)$ \\
\hline Third-line or greater & N/A & N/A & $251.6(305.2)$ \\
\hline \multicolumn{4}{|c|}{ Time to switch anti-TNFa biologic therapy(days), mean (SD) ${ }^{c}$} \\
\hline First-line & N/A & $349.5(308.7)$ & $326.2(239.9)$ \\
\hline Second-line & N/A & N/A & $127.8(197.9)$ \\
\hline Third-line or greater & N/A & N/A & $40.2(49.8)$ \\
\hline \multicolumn{4}{|c|}{ Time to first modification of anti-TNFa biologic therapy (days), mean (SD) d,e } \\
\hline First-line & $119.4(208.7)$ & $58.4(102.7)$ & $219.8(295.4)$ \\
\hline Second-line & N/A & $189.5(226.0)$ & $76.1(238.9)$ \\
\hline Third-line or greater & N/A & N/A & $24.3(33.3)$ \\
\hline \multicolumn{4}{|c|}{ Time from first modification of anti-TNFa biologic therapy to switch (days), mean (SD) $)^{f}$} \\
\hline First-line & N/A & $385.3(277.1)$ & $143.5(199.0)$ \\
\hline Second-line & N/A & N/A & $38.1(53.7)$ \\
\hline Third-line or greater & N/A & N/A & $42.0(65.6)$ \\
\hline
\end{tabular}

PSA psoriatic arthritis, N/A not available, SD standard deviation, TNFa tumor necrosis factor-a

${ }^{2}$ Anti-TNFa biologic therapy refers to the following anti-TNFa agents: etanercept, adalimumab, infliximab, and golimumab

${ }^{b}$ Persistent use was defined as time from initiation of the line of treatment to discontinuation (a gap in treatment of $>60$ days) of the line of treatment or switch to the next line of treatment (whichever came first)

"Time to switch is defined as time from initiation of the line of anti-TNFa biologic treatment to switch to the next line of anti-TNFa biologic treatment

${ }^{\mathrm{d}}$ Time to first modification of anti-TNFa biologic therapy was defined as time from initiation of the line of anti-TNFa biologic treatment to first modification on that line of treatment

'Modification of anti-TNFa biologic therapy included: biologic dose increase or dose decrease, DMARD added, changed, removed, or DMARD dose increase/decrease; Benchmark DMARD to identify first-line DMARD

change: most recent DMARD in 60-day prior to index biologics; Benchmark DMARD to identify second-/third-line DMARD change: most recent DMARD in the previous line

'Time from first modification of anti-TNFa biologic therapy to switch was defined as time from first modification on the line of anti-TNFa biologic treatment to switch to the next line of treatment 
more lines of therapy (219.8 [295.4] days or 7.3 months). In patients who received three or more lines of therapy during the 3-year follow-up period, time to switch and time to first treatment modification were progressively shorter with each new line of therapy. Time from first modification of therapy to treatment switch was longer for patients who switched to a second line of therapy (mean [SD]; 385.3 days [277.1] or 12.8 months) compared with those who switched to a third- or greater line of therapy (143.5 [199.0] days or 4.8 months) (Table 2).

\section{Treatment modification of anti-TNFa biologic therapy}

Modification of first-line anti-TNF $\alpha$ biologic treatment occurred in $21.1 \%$ of patients across all lines of therapy over the follow-up period. Patients who did not switch had fewer first-line treatment modifications (19.8\%) compared with patients who switched to a second- (31.9\%) or thirdor greater $(32.4 \%)$ line of therapy during the follow-up period (Table 3). In all patients, the most common modifications to first-line anti-TNF $\alpha$ biologic therapy were the addition or removal of a DMARD, and change to another DMARD (Table 3). During their second-line of therapy, patients who received only two lines of therapy often added a DMARD (13.9\%), while those who received at least three or more lines of therapy commonly discontinued a DMARD (21.6\%). During their third-line or greater of therapy, the addition of a DMARD (21.6\%) or removal of a DMARD $(10.8 \%)$ were the most common treatment

Table 3 Summary of treatment modification for anti-TNFa biologic therapy in patients with PsA for the 3-year follow-up

\begin{tabular}{|c|c|c|c|}
\hline & $\begin{array}{l}\text { Patients With Only First-line } \\
\text { Anti-TNFa Biologic } \\
\text { Therapy }(n=881)^{\mathrm{a}}\end{array}$ & $\begin{array}{l}\text { Patients With Second-line } \\
\text { Anti-TNFa Biologic } \\
\text { Therapy }(n=72)^{\mathrm{a}}\end{array}$ & $\begin{array}{l}\text { Patients with Third-line } \\
\text { or Greater of Anti-TNFa } \\
\text { Biologic Therapy }(n=37)^{\mathrm{a}} \\
\end{array}$ \\
\hline \multicolumn{4}{|l|}{ First-line, n (\%) } \\
\hline Anti-TNFa increase & $6(0.7)$ & 0 & 0 \\
\hline Anti-TNFa decrease & $7(0.8)$ & 0 & $1(2.7)$ \\
\hline DMARD add-on & $74(8.4)$ & $8(11.1)$ & $7(18.9)$ \\
\hline DMARD removal & $59(6.7)$ & $12(16.7)$ & $2(5.4)$ \\
\hline DMARD drug change ${ }^{b}$ & $27(3.1)$ & $2(2.8)$ & $2(5.4)$ \\
\hline DMARD dose increase & $2(0.2)$ & $1(1.4)$ & 0 \\
\hline DMARD dose decrease & $2(0.2)$ & 0 & 0 \\
\hline Any of the above & $177(19.8)$ & $23(31.9)$ & $12(32.4)$ \\
\hline \multicolumn{4}{|l|}{ Second-line, n (\%) } \\
\hline Anti-TNFa increase & N/A & $2(2.8)$ & 0 \\
\hline Anti-TNFa decrease & N/A & $2(2.8)$ & 0 \\
\hline DMARD add-on & N/A & $10(13.9)$ & 0 \\
\hline DMARD removal & N/A & $4(5.6)$ & $8(21.6)$ \\
\hline DMARD drug change ${ }^{b}$ & N/A & $3(4.2)$ & $2(5.4)$ \\
\hline DMARD dose increase & N/A & 0 & 0 \\
\hline DMARD dose decrease & N/A & 0 & 0 \\
\hline Any of the above & N/A & $21(29.2)$ & $10(27.0)$ \\
\hline \multicolumn{4}{|l|}{ Third-line or greater, n (\%) } \\
\hline Anti-TNFa increase & N/A & N/A & 0 \\
\hline Anti-TNFa decrease & N/A & N/A & 0 \\
\hline DMARD add-on & N/A & N/A & $8(21.6)$ \\
\hline DMARD removal & N/A & N/A & $4(10.8)$ \\
\hline DMARD change ${ }^{b}$ & N/A & N/A & 0 \\
\hline DMARD dose increase & N/A & $\mathrm{N} / \mathrm{A}$ & 0 \\
\hline DMARD dose decrease & N/A & N/A & 0 \\
\hline Any of the above & N/A & N/A & $12(32.4)$ \\
\hline
\end{tabular}

DMARD disease-modifying antirheumatic drug, TNFa tumor necrosis factor-a

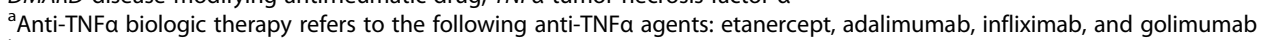

${ }^{b}$ First-line DMARD change was the most recent DMARD in 60-day prior to index anti-TNFa biologic treatment and second- and third-line or greater DMARD

change was the most recent DMARD in the previous line 
modifications for patients with three or more lines of therapy. Changes in dose of anti-TNF $\alpha$ biologic or DMARD therapy were uncommon $(\leq 2.8 \%)$ across the all lines of therapy for both patients who did and did not switch.

\section{Medical and pharmacy costs}

PPPM medical costs were less than PPPM pharmacy costs across all lines of treatment over the 3-year follow-up period (Table 4). PPPM medical costs were greater for patients who did not switch (mean [SD]; \$322 [\$1854]) than for those who switched to a second- (\$167 [\$363]) or third- or greater $(\$ 217[\$ 86])$ line of anti-TNFa biologic therapy. In patients who switched to three or more lines of therapy, the PPPM medical costs of the first-line therapy were higher (\$282 [\$595]) than the second- (\$79 [\$99]) or third- or greater (\$107 [\$88]) line of therapy. Overall, PPPM pharmacy costs were higher for patients with three of more lines of anti-TNF $\alpha$ biologic therapy (mean [SD]; \$2539 [\$1115]) compared with those who did not switch therapy ( $\$ 1985$ [\$833]) or switched to a second-line of therapy (\$2045 [\$650]). Switching to a second-line of antiTNF $\alpha$ biologic therapy was associated with an increase in pharmacy costs. In the group of PsA patients who received three or more lines of anti-TNF $\alpha$ biologic therapy, PPPM pharmacy costs for the third- or greater line of therapy were lower (mean [SD]; \$2126 [\$2551]) than the first(\$2515 [\$1800]) and second-line (\$2947 [\$1927]) therapies.

\section{Discussion}

In this descriptive claims-based study, treatment patterns differed among PsA patients who remained on their firstline of anti-TNF $\alpha$ biologic therapy compared with those who switched to additional lines of anti-TNFa biologic therapy. PsA patients who remained on their first-line antiTNF $\alpha$ biologic therapy showed longer persistence and fewer treatment modifications of the first-line therapy compared to those who switched to a second-, third- or greater line of therapy. Time to first-line treatment modification was longer for patients who switched to third- or greater lines of therapy than for those who did not switch or switched to second-line. Time-to-switch and time to firstline modification was progressively shorter with each line of therapy for patients who received third- or greater line. PPPM medical costs were greater for patients who did not switch (\$322) than for patients who switched to a second(\$167) or third- or greater line (\$217) of therapy. PPPM pharmacy costs were higher than medical costs, and were greater for patients with three or more lines of anti-TNFo biologic therapy (\$2539) compared with those with only a first- (\$1985) or a second-line (\$2045) of therapy.

Similar to other US studies, our study found that etanercept and adalimumab were the most common index anti-TNF $\alpha$ biologic therapies [31-35]. We also found that these two drugs were the most frequent anti-TNFa biologic agents used in patients who switched to other lines of therapy. Reasons for differences in treatment

Table 4 Mean medical and pharmacy cost PPPM of PSA patients receiving anti-TNFa therapy for the 3-year follow-up ${ }^{\text {ab }}$

\begin{tabular}{|c|c|c|c|}
\hline & $\begin{array}{l}\text { Patients With Only } \\
\text { First-line Anti-TNFa } \\
\text { Biologic Therapy } \\
(n=881)^{c}\end{array}$ & $\begin{array}{l}\text { Patients With Second-line } \\
\text { Anti-TNFa Biologic } \\
\text { Therapy } \\
(n=72)^{c}\end{array}$ & $\begin{array}{l}\text { Patients With Third-line } \\
\text { or Greater Anti-TNFa } \\
\text { Biologic Therapy } \\
(n=37)^{c}\end{array}$ \\
\hline \multicolumn{4}{|c|}{ Medical Cost PPPM, Mean (SD) ${ }^{d}$} \\
\hline First-line & $\$ 322(\$ 1854)$ & $\$ 127(\$ 247)$ & $\$ 282(\$ 595)$ \\
\hline Second-line & $\mathrm{N} / \mathrm{A}$ & $\$ 156(\$ 291)$ & $\$ 79(\$ 99)$ \\
\hline Third-line or greater & N/A & N/A & $\$ 107(\$ 88.0)$ \\
\hline Overall & $\$ 322(\$ 1854)$ & $\$ 167(\$ 363)$ & $\$ 217(\$ 86.0)$ \\
\hline \multicolumn{4}{|c|}{ Pharmacy Cost PPPM Mean (SD) } \\
\hline First-line & $\$ 1985(\$ 833)$ & $\$ 2082(\$ 836)$ & $\$ 2515(\$ 1800)$ \\
\hline Second-line & N/A & $\$ 2114(\$ 778)$ & $\$ 2947(\$ 1927)$ \\
\hline Third-line or greater & N/A & N/A & $\$ 2126(\$ 2551)$ \\
\hline Overall & $\$ 1985(\$ 833)$ & $\$ 2045(\$ 650)$ & $\$ 2539(\$ 1115)$ \\
\hline
\end{tabular}

${ }^{a}$ The value for each of the medical and pharmacy costs was calculated as total PPPM cost incurred from initiation of an anti-TNFa biologic treatment to discontinuation of treatment or end of the 3-year follow-up period (whichever came first) divided by the number of covered members per months from initiation to treatment discontinuation or end of the follow-up period (whichever came first)

${ }^{b}$ Costs of capitation patients were replaced with fee-for-service proxy; all costs were adjusted by consumer price index

'Biologic therapy refers to the following anti-TNFa agents: etanercept, adalimumab, infliximab, and golimumab

${ }^{\mathrm{d}}$ Medical cost $=$ hospitalization cost $+\mathrm{ER}$ cost + office visit cost. Number of months is defined as the rounding of number of days on treatment divided by 30 . If number of months equals to 0 , then it is assigned as 1

ePharmacy cost $=$ Biologic treatment cost + DMARD treatment cost

DMARD disease-modifying antirheumatic drug, ER emergency room, PSA psoriatic arthritis, PPPM per patient per month, SD standard deviation, TNFa tumor necrosis factor-a 
patterns across lines of therapy groups are not clear, but may be influenced by dissimilarities in response to antiTNF $\alpha$ biologic therapy, comorbidities, health insurance, change of physician, adverse events (AEs), disease characteristics, disease severity, or patient preference [6, 24, $27,34,36,37]$. Gender may also be another factor that has influenced switching [34]. As we observed, a lower percentage of females persisted on their first-line therapy compared with those who switched to either a secondor third- or greater line of anti-TNFo biologic treatment. In addition, several non-US studies found that women with PsA have shorter anti-TNF $\alpha$ biologic drug survival than men [52-54]. The increase in switching and the rate of modification with each line of therapy observed in patients who switched to three or more lines of therapy may indicate a lack of treatment response, poor tolerance, and/or high disease severity in these patients. In support of this, one prior non-US study found that lack of treatment effect and AEs were the main reasons why patients with PsA switched their anti-TNF $\alpha$ biologic treatment [52].

Our findings are comparable to that of other US studies which found that the rate of switching anti-TNF $\alpha$ biologic treatment over 1 year is low in PsA patients (range 2.8 to $25 \%$ ) [31-35]. Non-US studies have also found that only a minority of PsA patients switch antiTNF $\alpha$ biologic therapy within 1 year [54-56]. In previous US studies, patients who did not switch either remained on their index anti-TNF $\alpha$ biologic, restarted their index therapy after a treatment gap, or discontinued therapy [31-35]. We did not evaluate the rate of restarting or discontinuation of therapy.

Similar to the US study in 2014 by Zhang et al. [31], we found that, for the overall study population, the rate of treatment modification was low, with the most common modifications being the addition or removal of a DMARD. Zhang et al. found that $7 \%$ of PsA patients added a nonbiologic DMARD to their index anti-TNFa biologic therapy [31]. Our findings expand on those of Zhang et al., who did not assess treatment patterns associated with multiple lines of therapy. In our study, modification of first-line therapy was more common in patients with multiple lines of therapy compared with those who did not switch. We found that patients who had three or more lines of therapy added a DMARD to their first-line antiTNF $\alpha$ biologic therapy at a higher rate $(18.9 \%)$ compared with those who did not switch $(8.4 \%)$ or who switched to second-line therapy $(11.1 \%)$ over the 3-year follow-up period. We also found that about $14 \%$ of patients that switched to second-line TNF $\alpha$ biologic therapy added a DMARD to their second-line anti-TNF $\alpha$ biologic therapy. In contrast, no patients who switched to three or more lines of therapy added a DMARD to their second-line therapy; instead, $22 \%$ removed a DMARD. Currently, it is unclear what factors influence the rate and type of antiTNF $\alpha$ biologic treatment modification.

Previous US studies assessed the direct healthcare costs of anti-TNF $\alpha$ biologic therapy [35, 38-40]. They also did not evaluate the influence of switching on drug and healthcare costs [35, 38-40]. We found monthly medical costs were highest for patients who did not switch and lowest for those that switched to two lines of therapy over the 3-year follow-up period. In patients who switched to three or more lines of anti-TNF $\alpha$ biologic therapy, first-line therapy was associated with higher medical costs than second- or third- or greater lines of treatment, which had similar associated medical costs. Monthly pharmacy costs were higher in patients who switched compared with those who did not and highest in those that switched to at least three lines of treatment. The higher pharmacy costs with switching may indicate a need for additional medication possibly due to dose escalation, disease progression, or the presence of comorbidities in these patients. The cost of DMARDs compared with anti-TNF $\alpha$ biologic therapy was not differentiated in our analysis; hence, it is not clear how these therapies influenced overall pharmacy costs.

Although several prior US studies have evaluated the cost of anti-TNF $\alpha$ biologic treatment in PsA [32, 35, 3840], our study is the first to assess costs associated with switching to multiple lines of anti-TNF $\alpha$ biologic therapy. Direct comparison between our study and prior studies is difficult due to methodological differences in determining costs. However, in general across the studies, the annual cost for first-line therapy with anti-TNF $\alpha$ biologic treatment per patient ranged from about $\$ 17,000$ to $\$ 29,000[32,35,39,40]$, which is similar to the annual pharmacy cost for first-line treatment of about $\$ 24,000$ seen in our study.

The current study is a retrospective observational analysis of administrative claims databases with descriptive findings only. In addition, we used claims data that did not capture the reasons for switching. Therefore, we do not know how treatment response, physician beliefs, tolerability, efficacy, treatment modification, or treatment discontinuation influenced switching. This study was limited to PsA patients with commercial health coverage of Medicare. Consequently, it only evaluated PsA patients during the 3-year study period and it is unclear if the findings are translatable to those that are uninsured or on Medicaid. In addition, the limited sample size in the latter lines of therapy limit our ability to generalize our findings to a larger PsA population. Our study is also limited by that fact we only evaluated continuous users. We also excluded patients who ceased therapy for $>60$ days; therefore, we did not capture patients who stopped anti-TNF $\alpha$ biologic treatment and subsequently restarted with the same or different treatment. Finally, diagnoses on claims may be coded incorrectly or not 
coded at all, thereby potentially introducing measurement error with respect to ICD-9 based variables. We also did not take into consideration the potential effect of rebates, discounts, or other price concessions.

\section{Conclusion}

This descriptive claims-based study found PsA patient treatment patterns and healthcare costs differed depending on the number of times a patient switched their anti-TNF $\alpha$ biologic therapy. Most PsA patients remained on their first-line of therapy over the 3-year study period. Overall, the rate of treatment modification was low with patients who did not switch treatment having the lowest rate of modification. Time to switch and time to first treatment modification was progressively shorter for patients who received at least three lines of therapy-potentially an indication of reduced response. The highest PPPM medical costs were in patients that did not switch and the highest PPPM pharmacy costs occurred in patients with three or more lines of anti-TNF $\alpha$ biologic therapy. The findings of this give healthcare providers a better understanding of the real-world treatment pattern and economic impact of PsA.

\section{Abbreviations \\ AAD, American Academy of Dermatology; anti-TNFa, anti-tumor necrosis factor alpha; AS, Ankylosing spondylitis; DMARD, Disease-modifying antirheumatic drug; ER, Emergency room; EULAR, European League Against Rheumatism; FFS, Fee-for-service; GRAPPA, Group for Research and Assessment of Psoriasis and Psoriatic Arthritis; HMOs, Health maintenance organizations; ICD-9-CM, International Classification of Diseases, Ninth Revision, Clinical Modification; MTX, Methotrexate; N/A, Not available; NSAIDs, Non-steroidal anti-inflammatory drugs; POS, Point of service; PPPM, Per patient per month; PsA, Psoriatic arthritis; RA, Rheumatoid arthritis; SD, Standard deviation; US, United States}

\section{Acknowledgements}

Write All, Inc. received funding for its services from Novartis Pharmaceuticals Corporation. Michelle A. Adams, BSJ, MA of Write All Inc. and a consultant to Write All Inc, Tara Cowling, MA, MSc of Medlior Health Outcomes Research Ltd., provided medical writing and editorial assistance for this manuscript.

\section{Funding}

Funding was provided by Novartis Pharmaceuticals Corporation, East Hanover, NJ, USA.

\section{Availability of data and materials \\ Data were purchased and accessed from The Truven Health MarketScan ${ }^{\circledR}$ Research Databases, proprietary US research databases, which provide datasets detailed at the patient level to for representation of the continuum of care. Data are not to be shared due to the proprietary nature. All study data were accessed using techniques compliant with the Health Insurance Portability and Accountability Act of 1996, and no identifiable or protected health information was extracted during the course of the study, hence, the study did not require informed consent or institutional review board approval.}

\section{Authors' contributions}

All listed authors (JP, YL, ML, VH, ZEO, MT) have met the criteria for authorship set for by the International Committee for Medical Journal Editors and the BMC Musculoskeletal Disorders, and have contributed equally to the study design, writing, and revision of manuscript drafts as well as approved the final draft. $Y L$ and $M L$ collected and analyzed the data and all authors helped interpret the final data for manuscript preparation.

\section{Competing interests}

Drs. Palmer, Li, Herrera, and Ozturk are employees of Novartis Pharmaceuticals Corporation. Minlei Liao is a senior analyst at KMK Consulting Inc., and works as a consultant for Novartis Pharmaceuticals Corporation. Melody Tran is fellow from Scott \& White Health Plan and the College of Pharmacy, The University of Texas at Austin and works in Health Economics and Outcomes Research fellow at Novartis Pharmaceuticals Corporation. The Authors declare that they have no competing interest.

\section{Consent for publication}

Not applicable.

\section{Ethics approval and consent to participate}

All study data were accessed using techniques compliant with the Health Insurance Portability and Accountability Act of 1996, and no identifiable or protected health information was extracted during the course of the study, hence, the study did not require informed consent or institutional review board approval.

\section{Author details}

${ }^{1}$ Immunology and Dermatology, Health Economics \& Outcomes Research, Novartis Pharmaceuticals Corporation, One Health Plaza, East Hanover, NJ 07936-1080, USA. ²Outcomes Research Methods \& Analytics, US Health Economics \& Outcomes Research, Novartis Pharmaceuticals Corporation, East Hanover, NJ 07936-1080, USA. ${ }^{3}$ KMK Consulting, Inc, Morristown, NJ 07960-1080, USA. ${ }^{4}$ Scott \& White Health Plan, Temple, TX/College of Pharmacy, The University of Texas at Austin, Austin, TX 78705, USA. ${ }^{5}$ Immunology and Dermatology Medical Affairs Department, Novartis Pharmaceuticals Corporation, East Hanover, NJ 07936-1080, USA.

Received: 24 October 2015 Accepted: 27 May 2016

Published online: 14 June 2016

\section{References}

1. Spondyloarthritis (Spondyloarthropathies). http://www.rchsd.org/ documents/2014/02/spondyloarthritis.pdf. Accessed October 202014.

2. Sieper J, Rudwaleit M, Baraliakos X, Brandt J, Braun J, Burgos-Vargas R, Dougados M, Hermann KG, Landewe R, Maksymowych W et al. The Assessment of SpondyloArthritis international Society (ASAS) handbook: a guide to assess spondyloarthritis. Ann Rheum Dis. 2009;68 Suppl 2:ii1-44.

3. Rudwaleit M, Landewe R, van der Heijde D, Listing J, Brandt J, Braun J, Burgos-Vargas R, Collantes-Estevez E, Davis J, Dijkmans B et al. The development of Assessment of SpondyloArthritis international Society classification criteria for axial spondyloarthritis (part I): classification of paper patients by expert opinion including uncertainty appraisal. Ann Rheum Dis. 2009;68(6):770-6.

4. Rudwaleit $M$, van der Heijde D, Landewe R, Akkoc N, Brandt J, Chou CT, Dougados M, Huang F, Gu J, Kirazli Y et al. The Assessment of SpondyloArthritis International Society classification criteria for peripheral spondyloarthritis and for spondyloarthritis in general. Ann Rheum Dis. 2011; 70(1):25-31.

5. Cantini F, Niccoli L, Nannini C, Kaloudi O, Bertoni M, Cassara E. Psoriatic arthritis: a systematic review. Int J Rheum Dis. 2010;13(4):300-17.

6. Lee S, Mendelsohn A, Sarnes E. The burden of psoriatic arthritis: a literature review from a global health systems perspective. P \& T. 2010;35(12):680-9.

7. Krueger GG. Clinical features of psoriatic arthritis. Am J Manag Care. 2002:8(6 Suppl):S160-170.

8. About Psoriatic Arthritis. https://www.psoriasis.org/about-psoriatic-arthritis. Accessed 30 Jun 2015.

9. Naldi L, Mercuri SR. Epidemiology of comorbidities in psoriasis. Dermatol Ther. 2010;23(2):114-8.

10. Husted JA, Thavaneswaran A, Chandran V, Eder L, Rosen CF, Cook RJ, Gladman DD. Cardiovascular and other comorbidities in patients with psoriatic arthritis: a comparison with patients with psoriasis. Arthritis Care Res. 2011;63(12):1729-35.

11. Rosen CF, Mussani F, Chandran V, Eder L, Thavaneswaran A, Gladman DD. Patients with psoriatic arthritis have worse quality of life than those with psoriasis alone. Rheumatology. 2012;51(3):571-6. 
12. Ackermann C, Kavanaugh A. Economic burden of psoriatic arthritis. Pharmacoeconomics. 2008;26(2):121-9.

13. American Academy of Dermatology Work G, Menter A, Korman NJ, Elmets CA, Feldman SR, Gelfand JM, Gordon KB, Gottlieb A, Koo JY, Lebwohl M et al. Guidelines of care for the management of psoriasis and psoriatic arthritis: section 6. Guidelines of care for the treatment of psoriasis and psoriatic arthritis: case-based presentations and evidence-based conclusions. J Am Acad Dermatol. 2011;65(1):137-74.

14. Gossec L, Smolen JS, Gaujoux-Viala C, Ash Z, Marzo-Ortega H, van der Heijde D, FitzGerald O, Aletaha D, Balint P, Boumpas D et al. European League Against Rheumatism recommendations for the management of psoriatic arthritis with pharmacological therapies. Ann Rheum Dis. 2012;71(1):4-12

15. Smolen JS, Braun J, Dougados M, Emery P, Fitzgerald O, Helliwell P, Kavanaugh A, Kvien TK, Landewe R, Luger T et al. Treating spondyloarthritis, including ankylosing spondylitis and psoriatic arthritis, to target: recommendations of an international task force. Ann Rheum Dis. 2014;73(1):6-16.

16. Coates LC. Treating to target in psoriatic arthritis. Curr Opin Rheumatol. 2015;27(2):107-10

17. Day MS, Nam D, Goodman S, Su EP, Figgie M. Psoriatic arthritis. J Am Acad Orthop Surg. 2012;20(1):28-37.

18. HUMIRA (adalimumab) Prescribing Information. http://www.rxabbvie.com/ pdf/humira.pdf Accessed July 152015

19. Enbrel ${ }^{\oplus}$ (etanercept) Prescribing Information. http://pi.amgen.com/united_ states/enbrel/derm/enbrel_pi.pdf. Accessed 30 Jun 2015.

20. SIMPONI (golimumab) prescribing informatiion. http://www.simponi.com/ shared/product/simponi/prescribing-information.pdf. Accessed 18 Nov 2014.

21. Remicade (infliximab) Prescribing Information. https://www.remicade.com/ shared/product/remicade/prescribing-information.pdf. Accessed 30 Jun 2015

22. CIMZIA (certolizumab pegol) Prescribing Information. http://www.cimzia. com/assets/pdf/Prescribing_Information.pdf. Accessed 27 Jul 2015.

23. STELARA (ustekinumab). Prescribing information. http://www.stelarainfo. com/. Accessed 27 Jul 2015.

24. Mease P. Psoriatic arthritis and spondyloarthritis assessment and management update. Curr Opin Rheumatol. 2013;25(3):287-96.

25. Ogdie-Beatty AR (2015) GRAPPA initiatives continue to chart the way for psoriasis, psoriatic arthritis. PM360-Rheumatology. http://www. pm360online.com/grappa-initiatives-continue-to-chart-the-way-for-psoriasis -psoriatic-arthritis/. Accessed 30 Jun 2015.

26. Nash P, Lubrano E, Cauli A, Taylor WJ, Olivieri I, Gladman DD. Updated guidelines for the management of axial disease in psoriatic arthritis. J Rheumatol. 2014:41(11):2286-9.

27. Felquer ML, Soriano ER. New treatment paradigms in psoriatic arthritis: an update on new therapeutics approved by the U.S. Food and Drug Administration. Curr Opin Rheumatol. 2015;27(2):99-106.

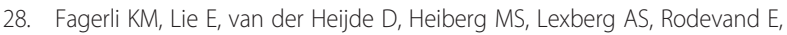
et al. The role of methotrexate co-medication in TNF-inhibitor treatment in patients with psoriatic arthritis: results from 440 patients included in the NOR-DMARD study. Ann Rheum Dis. 2014;73(1):132-7.

29. Coates LC, Kavanaugh AF, Mease PJ, Ritchlin CT. GRAPPA Treatment Recommendations: An Update from the GRAPPA 2014 Annual Meeting and GRAPPA Meeting Adjacent to the 2014 ACR Meeting. J Rheumatol. 2015;42: 1052-5

30. Coates LC, Ritchlin CT, Kavanaugh AF. GRAPPA treatment recommendations: an update from the GRAPPA 2013 Annual Meeting. J Rheumatol. 2014;41(6):1237-9.

31. Zhang HF, Gauthier G, Hiscock R, Curtis JR. Treatment patterns in psoriatic arthritis patients newly initiated on oral nonbiologic or biologic diseasemodifying antirheumatic drugs. Arthritis Res Ther. 2014;16(4):420.

32. Zhu B, Edson-Heredia E, Gatz UL, Guo J, Shuler CL. Treatment patterns and health care costs for patients with psoriatic arthritis on biologic therapy: a retrospective cohort study. Clin Ther. 2013;35(9):1376-85.

33. Yeaw J, Watson C, Fox KM, Schabert VF, Goodman S, Gandra SR. Treatment patterns following discontinuation of adalimumab, etanercept, and infliximab in a US managed care sample. Adv Ther. 2014;31(4):410-25.

34. Bonafede M, Fox KM, Watson C, Princic N, Gandra SR. Treatment patterns in the first year after initiating tumor necrosis factor blockers in real-world settings. Adv Ther. 2012;29(8):664-74.

35. Howe A, Eyck LT, Dufour R, Shah N, Harrison DJ. Treatment patterns and annual drug costs of biologic therapies across indications from the Humana commercial database. J Manag Care Spec Pharm. 2014;20(12):1236-44.
36. Ogdie A, Schwartzman S, Husni ME. Recognizing and managing comorbidities in psoriatic arthritis. Curr Opin Rheumatol. 2015:27(2):118-26.

37. Helliwell PS, FitzGerald O, Fransen J, Gladman DD, Kreuger GG, Callis-Duffin $\mathrm{K}$, et al. The development of candidate composite disease activity and responder indices for psoriatic arthritis (GRACE project). Ann Rheum Dis. 2013;72(6):986-91.

38. Schabert VF, Watson C, Joseph GJ, Iversen P, Burudpakdee C, Harrison DJ. Costs of tumor necrosis factor blockers per treated patient using real-world drug data in a managed care population. J Manag Care Pharm. 2013;19(8): 621-30.

39. Wu N, Lee YC, Shah N, Harrison DJ. Cost of biologics per treated patient across immune-mediated inflammatory disease indications in a pharmacy benefit management setting: a retrospective cohort study. Clin Ther. 2014; 36(8):1231-41. 1241 e1231-1233.

40. Bonafede M, Joseph GJ, Princic N, Harrison DJ. Annual acquisition and administration cost of biologic response modifiers per patient with rheumatoid arthritis, psoriasis, psoriatic arthritis, or ankylosing spondylitis. J Med Econ. 2013;16(9):1120-8.

41. Danielson E: Health Research Data for the Real World: The MarketScan ${ }^{\oplus}$ Databases (White Paper). 2014.

42. B.R.I.D.G.E. to data. MarketScan Commercial Claims Encounters (USA). http:// www.bridgetodata.org/node/987. Accessed 15 Jun 2015.

43. (2012) Truven Health Analytics [homepage on the Internet]. http:// truvenhealth.com/your_healthcare_focus/research/marketscan_research_ databases.aspx. Accessed 11 Oct 2014.

44. Palmer JB, LI Y, Tsang Y, Liao M, Ozturk Z: Treatment patterns and costs for anti-TNFa therapy in patients with ankylosing spondylitis. Rheumatology (Sunnyvale) 2015, (in press).

45. Imuran (azathioprine) Prescribing Information. http://www.accessdata.fda.gov/ drugsatfda_docs/label/2011/016324s034s035lbl.pdf. Accessed 15 Jun 2015.

46. PLAQUENIL (hydroxychloroquine sulfate) Prescribing Information. http:// www.accessdata.fda.gov/drugsatfda_docs/label/2007/009768s041 lbl.pdf. Accessed 30 Jun 2015

47. ARAVA $^{\circledast}$ (leflunomide) Prescribing Information. http://products.sanofi.com. au/aus pi arava.pdf. Accessed 30 Jun 2015.

48. Azulfidine ${ }^{\oplus}$ (sulfasalazine) Prescribing Information. http://labeling.pfizer.com/ ShowLabeling.aspx?id=524. Accessed 30 Jun 2015.

49. Sandimmune ${ }^{\circledast}$ (cyclosporine) Prescribing Information. https://www.pharma. us.novartis.com/product/pi/pdf/sandimmune.pdf. Accessed 30 Jun 2015.

50. Methotrexate (Product Monograph). http://www.pfizer.ca/sites/g/files/ g10017036/f/201410/Methotrexate_0.pdf. Accessed 30 Jun 2015.

51. OTEZLA ${ }^{\oplus}$ (apremilast) Prescribing Information. http://www.otezlapro.com/ wp-content/uploads/2015/02/otezla-prescribing-information.pdf. Accessed 30 Jun 2015.

52. Glintborg B, Ostergaard M, Krogh NS, Andersen MD, Tarp U, Loft AG, Lindegaard HM, Holland-Fischer M, Nordin H, Jensen DV et al. Clinical response, drug survival, and predictors thereof among 548 patients with psoriatic arthritis who switched tumor necrosis factor alpha inhibitor therapy: results from the Danish Nationwide DANBIO Registry. Arthritis Rheum. 2013:65(5):1213-23.

53. Glintborg B, Ostergaard M, Dreyer L, Krogh NS, Tarp U, Hansen MS, Rifbjerg-Madsen S, Lorenzen T, Hetland ML. Treatment response, drug survival, and predictors thereof in 764 patients with psoriatic arthritis treated with anti-tumor necrosis factor alpha therapy: results from the nationwide Danish DANBIO registry. Arthritis Rheum. 2011;63(2):382-90.

54. Heiberg MS, Koldingsnes W, Mikkelsen K, Rodevand E, Kaufmann C, Mowinckel P, Kvien TK. The comparative one-year performance of anti-tumor necrosis factor alpha drugs in patients with rheumatoid arthritis, psoriatic arthritis, and ankylosing spondylitis: results from a longitudinal, observational, multicenter study. Arthritis Rheum. 2008; 59(2):234-40.

55. Glintborg B, Ostergaard M, Krogh NS, Tarp U, Manilo N, Loft AG, Hansen A, Schlemmer A, Fana V, Lindegaard HM et al. Clinical response, drug survival and predictors thereof in 432 ankylosing spondylitis patients after switching tumour necrosis factor alpha inhibitor therapy: results from the Danish nationwide DANBIO registry. Ann Rheum Dis. 2013;72(7):1149-55.

56. Fabbroni M, Cantarini L, Caso F, Costa L, Pagano VA, Frediani B, Manganelli S, Galeazzi M. Drug retention rates and treatment discontinuation among anti-TNF-alpha agents in psoriatic arthritis and ankylosing spondylitis in clinical practice. Mediators Inflamm. 2014:2014:862969. 